\section{Identification of Raspberry Cultivars by Nonradioactive DNA Fingerprinting}

\author{
Jean-Guy Parent and Danièl Pagé \\ Service de phytotechnie de Quèbec (MAPAQ), Complexe scientifique, \\ 2700, rue Einstein, Sainte-Foy, Qué GlP 3W8, Canada
}

Additional index words; Rubus, minisatellite DNA, oligonucleotide probe, RFLP

\begin{abstract}
Characterization and identification of 13 red raspberry (Rubus idaeus L.) and two purple raspberry $(R . \times$ neglectus Peck) cultivars were obtained by nonradioactive genetic fingerprinting. DNA from leaves was digested with $\mathrm{Hae}$ III and $\mathrm{Hin}$ f I restriction enzymes and probed with alkaline phosphatase-labeled oligonucleotide. All tested cultivars could be identified by a unique band pattern. No differences were noted within cultivars when the reproducibility of the fingerprints was evaluated by analyzing the effects of age of the raspberry plantation, developmental stage during the growing season, or position of the sampled leaf on stem. These results suggest that simple nonradioactive DNA fingerprinting can be routinely used to identify raspberry cultivars.
\end{abstract}

Up to now, red raspberry and purple raspberry cultivar identification for the production of certified plants has relied mostly on morphological traits. Fruit and flower characteristics have been most commonly used but are often absent, making authentication difficult for plants during vegetative growth, including plants micropropagated in vitro. This lack of a permanent and objective test sometimes leads to cultivar mislabeling (J.C. Cousineau and D.J. Donnelly, personal communication). Raspberry cultivars are propagated by asexual reproduction and hence can be considered to be clones with no or with low levels of genetic variation. This genetic uniformity has allowed the development of simple laboratory tests for cultivar identification based on electrophoretic analysis of isoenzymes (Cousineau and Donnelly, 1989). Unfortunately, despite the analysis of several enzymes, some cultivars cannot be distinguished from one another. These findings preclude the use of isoenzyme analysis as the sole test in certification programs.

Recently, a powerful DNA fingerprinting test, initially described for humans (Jeffreys et al., 1985), was found to be relevant to the analysis of Rosaceae species (Nybom, 1990; Nybom and Hall, 1991; Nybom and Schaal, 1990; Nybom et al., 1989, 1990). The test allowed identification of individuals or clones through the analysis of hypervariable minisatellite DNA present in many Rubus spp. Applications included the capacity to distinguish a few raspberry cultivars from each other by using ${ }^{32} \mathrm{P}$-labeled probes. Safety

Received for publication 25 Nov. 1991. Accepted for publication 10 June 1992. We thank certified and. commercial growers Roger Labrecque and Ferme Patoine for their collaboration in the collection of field samples. We also thank Alain Asselin, Lava1 Univ., and Marc G. Fortin, McGill Univ., for their helpful criticism of the manuscript. The cost of publishing this paper was defrayed in part by the payment of page charges. Under postal regulations, this paper therefore must be hereby marked advertisement solely to indicate this fact. with slightly different lengths (see text for details). edged by the certification program of the province of Quebec. Except where indicated, young but fully expanded leaves were collected and kept on ice during transport to the laboratory. Midribs were removed, and the remaining leaf material was cut in 3- to 5-mm squares, and $1-\mathrm{g}$ portions were frozen at - 80C until DNA extraction.

DNA isolation and analysis of fingerprints. DNA was extracted and purified according to the hexadecyltrimethylammonium bromide (CTAB) method for lyophilized plant leaves of Saghai-Maroof et al. (1984) with the modifications of Doyle and Doyle (1987) for fresh tissue. To estimate DNA concentration, samples of raspberry DNA were compared with dilutions of known concentrations of salmon sperm DNA after agarose gel electrophoresis and ethidium bromide staining. Levels of contamination by proteins and by polyphenols/carbohydrates were assessed, respectively, using $\mathrm{A}_{260}: \mathrm{A}_{280}$ and $\mathrm{A}_{260}: \mathrm{A}_{230}$ ratios measured by UV spectrophotometry (Logemann et al., 1987). For each fingerprint analysis, two DNA samples were digested with restriction enzymes Hae III and Hinf I. Seven micrograms of digested DNA was deposited in wells of $0.8 \%$ or $1.4 \%$ (w/ v) agarose gels $(20 \times 25 \mathrm{~cm})$ and subjected to electrophoresis in a Tris-acetate buffer system (Maniatis et al., 1982). Gels were treated and blotted onto nylon membranes, after which the DNA was W-bound to the membranes (Khandjian, 1987).

Transferred DNA was hybridized with enzyme-labeled DNA probes (SNAP DNA fingerprinting kit, Molecular Biosystems, San Diego). Such probes are alkaline phosphatase-linked, single-stranded, 22-mer oligonucleotides (Edman et al., 1988) corresponding to the core sequence of a human myoglobin minisatellite (Jeffreys et al., 1985). The protocol for chemiluminescent detection recommended by the manufacturer was followed except that LumiPhos 530 (Lumigen, Detroit, Mich.) was used as chemiluminescent substrate. For each gel, a sheet of Kodak X-

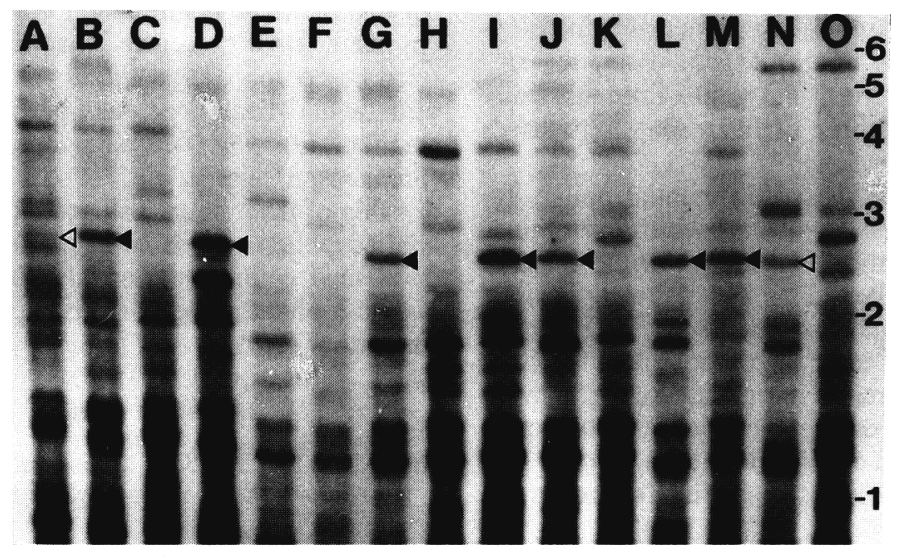

Fig. 1. Fingerprints of raspbeny cultivars from $\operatorname{Hinf} 1$ fragments separated in $0.8 \%$ agarose gel. Letters correspond to 'Anelma' (A), 'Bonanza' (B), 'Boyne' (C), 'Brandywine' (D), 'Comet' (E), 'Festival' (F), 'Gatineau' (G), 'Heritage' (H), 'Killarney' (I), 'Madawaska' (J), 'Nova' (K), 'Pathfinder' (L), 'Royalty' (M), 'Titan' (N), and 'Willamette' (0). Numbers correspond to the position of molecular weight markers $\left(\times 10^{-3}\right.$ base pairs). Open and closed arrowheads indicate the position of fragments 
Table 1. Similarity index values ${ }^{\mathrm{z}}$ for all pairwise comparisons of the raspberry cultivars.

\begin{tabular}{|c|c|c|c|c|c|c|c|c|c|c|c|c|c|c|c|}
\hline $\mathrm{BON}^{\mathrm{y}}$ & 0.60 & & & & & & & & & & & & & & \\
\hline BOY & 0.44 & 0.54 & & & & & & & & & & & & & \\
\hline BRA & 0.33 & 0.37 & 0.33 & & & & & & & & & & & & \\
\hline $\mathrm{COM}$ & 0.47 & 0.51 & 0.42 & 0.34 & & & & & & & & & & & \\
\hline FES & 0.59 & 0.50 & 0.40 & 0.34 & 0.64 & & & & & & & & & & \\
\hline GAT & 0.55 & 0.46 & 0.46 & 0.42 & 0.63 & 0.66 & & & & & & & & & \\
\hline HER & 0.48 & 0.49 & 0.36 & 0.38 & 0.38 & 0.48 & 0.42 & & & & & & & & \\
\hline KIL & 0.36 & 0.47 & 0.62 & 0.41 & 0.37 & 0.35 & 0.40 & 0.37 & & & & & & & \\
\hline MAD & 0.58 & 0.53 & 0.45 & 0.60 & 0.60 & 0.62 & 0.61 & 0.48 & 0.42 & & & & & & \\
\hline NOV & 0.56 & 0.70 & 0.56 & 0.38 & 0.48 & 0.44 & 0.45 & 0.41 & 0.50 & 0.52 & & & & & \\
\hline PAT & 0.34 & 0.42 & 0.38 & 0.34 & 0.38 & 0.34 & 0.44 & 0.43 & 0.47 & 0.40 & 0.38 & & & & \\
\hline ROY & 0.54 & 0.44 & 0.38 & 0.52 & 0.49 & 0.54 & 0.56 & 0.38 & 0.39 & 0.61 & 0.58 & 0.32 & & & \\
\hline TIT & 0.61 & 0.54 & 0.46 & 0.40 & 0.56 & 0.64 & 0.65 & 0.43 & 0.38 & 0.67 & 0.51 & 0.36 & 0.61 & & \\
\hline WIL & 0.67 & 0.49 & 0.46 & 0.31 & 0.52 & 0.50 & 0.53 & 0.33 & 0.28 & 0.51 & 0.53 & 0.24 & 0.54 & 0.66 & \\
\hline \multirow[t]{2}{*}{ AVE } & 0.51 & 0.50 & 0.45 & 0.39 & 0.49 & 0.50 & 0.52 & 0.42 & 0.41 & 0.54 & 0.50 & 0.37 & 0.49 & 0.53 & 0.47 \\
\hline & ANE & BON & BOY & BRA & $\mathrm{COM}$ & FES & GAT & HER & KIL & MAD & NOV & PAT & ROY & TIT & WIL \\
\hline
\end{tabular}

${ }^{2}$ Values correspond to the mean of two separate experiments with $0.8 \%$ or $1.4 \%$ agarose gels. Results from Hae III and Hinf I fingerprints were combined in each experiment.

y Names of cultivars are abbreviated by their first three letters. AVE = average index value.

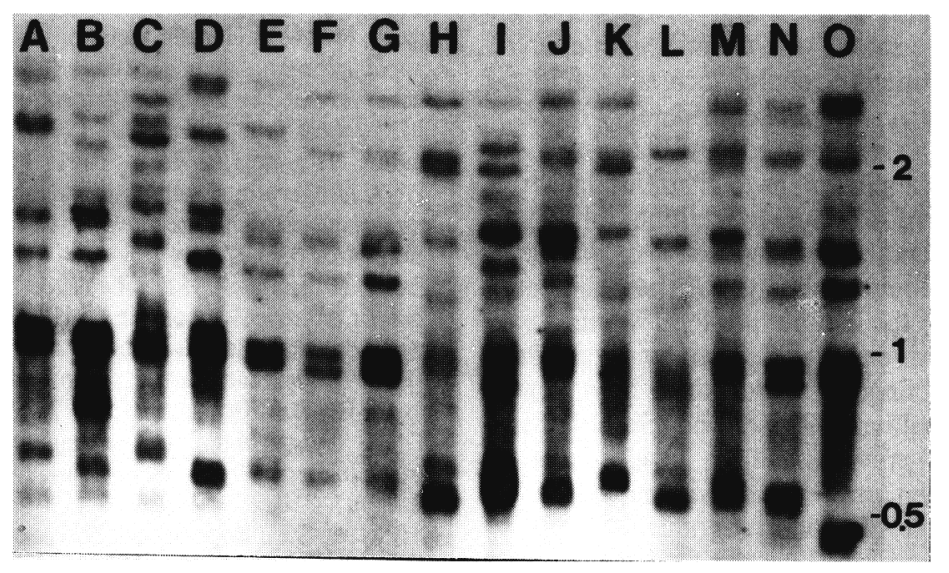

Fig. 2. Fingerprints of raspberry cultivars from Hue III fragments separated in $0.8 \%$ agarose gel. Letters and numbers are the same as for Fig. 1

Omat SB-5 was exposed to emitted light during $5 \mathrm{~h}$ at room temperature before photographic development. When some bands or patterns were too faint, another film was immediately exposed for a longer duration (maximum of 2 days). Standards (1 kb DNA Ladder, Gibco BRL, Gaithersburg, Md.) were included in the outer two lanes of all gels to allow determination of molecular weight and correspondence between gels.

Cultivar comparisons. Fingerprints of the raspberry cultivars were obtained from plants of a demonstration plantation at the SaintAugustin Research Station, Que. (Figs. 1 and 2). Two separate experiments were performed to obtain the best electrophoretic separation for different ranges of DNA molecular weights, one with $0.8 \%$ agarose gels and the other with $1.4 \%$ gels. We analyzed 40 bands from patterns of Hae III fragments of 500 to 3000 base pairs (bp) (with an average of 12.4 bands for each cultivar) and 24 bands from patterns of Hinf I fragments with a range of 1000 to 6000 base pairs (average of 9.7 bands). Smaller fragments could probably also reveal polymorphism but were not resolved well enough in our gel system to allow adequate analysis. Bands representing larger fragments were sometimes observed; these correspond to DNA fragments with restriction sites that are resistant to digestion and must not be considered of diagnostic value. We used only bands that were not present in all cultivars for the analysis. To compare banding patterns between cultivars, two sets of gels were used, one with an alphabetical arrangement of the cultivars and the other with a random disposition. Thus, four gels, of $0.8 \%$ and $1.4 \%$ agarose with two cultivar arrangements, were used to determine similar and dissimilar bands between cultivars. Banding patterns between cultivars varied greatly, but similar and dissimilar bands could be distinguished when all four gels were compared. For example, in Fig. 1, a 2.5-kbp band (marked with closed arrowheads) was present in patterns of cultivars in lanes B, $\mathrm{D}, \mathrm{G}, \mathrm{I}, \mathrm{J}, \mathrm{L}$, and $\mathrm{M}$, whereas a band of slightly lower molecular weight (open arrowheads) was present in lanes $\mathrm{A}$ and $\mathrm{N}$. The chance occurrence that any two cultivars shared an identical fingerprint was calculated to be a maximum of $2.6 \times 10^{-3}$ using the method of Nybom et al. (1989) and a single gel/enzyme combination. Thus, it is highly improbable that two cultivars would have the same banding pattern, especially since two experiments involving two restriction enzymes were performed. However, chance occurrence values depend on the number of bands analyzed and on the relationship of the cultivars used in the determination. Even if the probability of having two indistinguishable cultivars is low, it must not be completely rejected because the genetic base of cultivated raspberry is narrow (Dale et al., 1989 ).

Our fingerprint patterns were different from, and could not be compared with, those previously obtained for raspberry (Nybom and Hall, 1991; Nybom and Schaal, 1990; Nyborn et al., 1989), as we did not use the same probe (Ml3 probe vs. myoglobin minisatellite DNA). However, DNA restriction patterns of ornamental plants obtained with Hinf I had useful bands of 2000 to 5000 base pairs when the same type of probe as ours was used (Tzuri et al., 1991).

Similarity index values (Nybom et al., 1989) were calculated for each pair of cultivars by combining results from Hae III and Hinf I fingerprints. These index values are for comparative purposes, as their results depend on the number of chosen bands, the number of cultivars, resolution of the gels, etc. Every cultivar had its own specific fingerprints and the resulting index values ranged from 0.24 to 0.70 , with a mean of $0.47(\mathrm{Ta}-$ ble 1). Values could often be related to the degree of interrelatedness as deduced from pedigrees as observed for some Rubus cultivars (Nybom and Hall, 1991; Nybom et al., 1989). For example, 'Killarney' has low similarity index values with all cultivars except 'Boyne', which originated from a 'Chief' $\times$ 'Indian Summer' cross, like 'Killarney'. In addition, pairs of cultivars, like 'Titan' and 'Royalty', that could not be separated by isoenzyme analysis (Cousineau and Donnelly, 1989) were resolved effectively by analysis of their fingerprints. However, a high index value was not always related to close pedigrees. The purple raspberry 'Brandywine' ('NY631' $x$ 'Hilton') and the red raspberry 'Madawaska' ('Lloyd George' $x$ 'Newman 23') have distinct parentage but share a similarity index value of 0.60 , especially high for 'Brandywine' (average of 0.39).

Average index values (Table 1) indicate the degree of relationship of one cultivar with others. Most cultivars have similar average index values (LSD: 0.058; P: 0.10), except 'Brandywine', 'Pathfinder', 'Heritage', and 
'Killarney', which have lower values and could be considered less related to the others. The three former cultivars are different, as they are, respectively, a purple raspberry and two primocane-fruiting red raspberries. Genetic divergence could result from these characteristics, although the purple raspberry 'Royalty' does not have a low index value. For 'Killarney', a comparison with isoenzyme analysis of Cousineau and Donnelly (1989) was helpful. This cultivar had its own patterns for two out of five enzymes, reflecting its genetic distance as calculated from our fingerprints. Similar relations were observed for 'Brandywine' purple raspberry.

Fingerprint reproducibility. Fingerprint reproducibility was first checked with plants cultivated from the same original plant stock but differing in the duration of cultivation. In vitro plantlets, plants from the certification program (Foundation and Certified) and certified plants grown by a commercial grower for up to 6 years, represented a range of 11 years of culture. Seven of the cultivars were checked, and we could not find any fingerprint difference within cultivar. Fingerprints of all cultivars were obtained from leaves collected at three periods of the growing season (28 May and 10 and 29 July). Again, we detected no intracultivar variation. The same result was obtained when we compared leaves collected from the top, middle, or bottom of floricanes or from primocanes.

While the fingerprints are reproducible during the growing season, some technical aspects were affected by the physiological stage of the raspberry plants. DNA digestion by restriction enzymes is known to be inhibited by contaminants. By using the extraction method described, the level of contamination by polyphenols/carbohydrates of DNA was constant $\left(\mathrm{A}_{260}: \mathrm{A}_{230} 1.70 ; \mathrm{SD}\right.$, $0.16 ; \mathrm{n}, 50)$ up to the end of June (beginning of fruit formation), after which a sharp increase in contaminants was observed $\left(\mathrm{A}_{260}\right.$ : $\mathrm{A}_{230}$ 1.25; SD, 0.19; n, 66). Protein contamination followed the same pattern, but variations were less pronounced. These high levels of contaminants in DNA preparations are typical of plants of the Rosaceae family (Manning, 1991). Thus, large quantities of restriction enzyme coupled with long incubation periods were required to achieve complete digestion of many DNA extracts. Reduction of enzyme concentration or incubation time was successful with May or June samples but failed with many of those from late summer (unpublished). Extracts from primocane leaves were slighty less contaminated than those from floricanes. The number of years of field cultivation had no effect on contamination levels. However, contamination by polyphenols/carbohydrates of in vitro plants was high $\left(\mathrm{A}_{260}: \mathrm{A}_{230}, 1.34\right.$; SD, $0.18 ; \mathrm{n}, 8)$. Nevertheless, these DNA contaminants were not sufficient to impede the experiments, and we were able to digest the raspberry DNA and to obtain fingerprints with all kinds of plants.

We have shown that nonradioactive DNA fingerprinting is a reliable technique to identify raspberry cultivars considerably quicker than radioactivity procedures, reducing 5- to 10-day autoradiographs to chemiluminescent exposures of $<2$ days. In addition, reliability of the technique is independent of the plant age, developmental stage of the plant, and position of the leaf on the stem. Verification of identity is easily performed by direct comparisons of fingerprints with those from known standard cultivars. The reproducibility of the procedure provides a high level of confidence when used in the authentication of raspberry certification programs.

\section{Literature Cited}

Cousineau, J.C. and D.J. Donnelly. 1989. Identification of raspberry cultivars in vivo and in vitro using isoenzyme analysis. HortScience 24:490-492.

Dale, A., R.J. McNicol, P.P. Moore, and T.M. Sjulin. 1989. Pedigree analysis of red raspberry. Acta Hort. 262:35-39

Doyle, J.J. and J.L. Doyle. 1987. A rapid DNA isolation procedure for small quantities of fresh leaf tissue. Phytochemical Bul. 19:11-15.

Edman, J.C., M.E. Evans-Holm, J.E. Marich, and
J.L. Ruth. 1988. Rapid DNA fingerprinting using alkaline phosphatase-conjugated oligonucleotides. Nucleic Acids Res. 16:6235.

Jeffreys, A.J., V. Wilson, and S.L. Thein. 1985. Hypervariable 'minisatellite' regions in human DNA. Nature (London) 314:67-73.

Khandjian, E.W. 1987. Optimized hybridization of DNA blotted and fixed to nitrocellulose and nylon membranes. Bioltechnology 5:165-167.

Logemann, J., J. Schell, and L. Willmitzer. 1987. improved method for the isolation of RNA from plant tissues. Anal. Biochem. 163:16-20.

Maniatis, T., E.F. Fritsch, and J. Sambrook. 1982. Molecular cloning. A laboratory manual. Cold Spring Harbor Laboratory, Cold Spring Harbor, N.Y.

Manning, K. 1991. Isolation of nucleic acids from plants by differential solvent precipitation. Anal. Biochem. 195:45-50.

Murashige, T. and F. Skoog. 1962. A revised medium for rapid growth and bioassays with tobacco tissue cultures. Physiol. Plant. 15:473497.

Nybom, H. 1990. Genetic variation in ornamental apple trees and their seedlings (Malus, Rosaceae) revealed by DNA 'fingerprinting' with the M13 repeat probe. Hereditas 113:17-28.

Nybom, H. and H.K. Hall. 1991. Minisatellite DNA 'fingerprints' can distinguish Rubus cultivars and estimate their degree of relatedness. Euphytica 53:107-114.

Nybom, H. and B.A. Schaal. 1990. DNA "fingerprints" reveal genotypic distributions in natural populations of blackberries and raspberries (Rubus, Rosaceae). Amer. J. Bot. 77:883-888.

Nybom, H., B.A. Schaal, and S.H. Rogstad. 1989. DNA "fingerprints" can distinguish cultivars of blackberries and raspberries. Acta Hort. 262:305-310

Nybom, H., S.H. Rogstad, and B.A. Schaal. 1990. Genetic variation detected by use of the M13 "DNA fingerprint" probe in Malus, Prunus, and Rubus (Rosaceae). Theoretical Applied Genet. 79:153-156.

Saghai-Maroof, M.A., K.M. Soliman, R.A. Jorgensen, and R.W. Allard. 1984. Ribosomal DNA spacer-length polymorphism in barley: Mendelian inheritance, chromosomal location, and population dynamics. Proc. Natl. Acad. Sci. USA $81: 8014-8018$.

Tzuri, G., J. Hillel, U. Lavi, A. Haberfeld, and A. Vainstein. 1991. DNA fingerprint analysis of ornamental plants. Plant Sci. 76:91-97. 